\title{
Trabalhador com deficiência física: fragilidades e agravos autorreferidos
}

\author{
Worker with physical disability: weaknesses and disorders self referred \\ Trabajador con discapacidad física: debilidades y daños auto percibidos
}

\begin{abstract}
Débora Ribas Leal', Gisele Domingues de Mattos', Rosane Teresinha Fontana"
' Universidade Regional Integrada do Alto Uruguai e das Missões, Campus Santo Ângelo, Curso de Enfermagem (Graduanda). Santo Ângelo-RS, Brasil.

"Universidade Regional Integrada do Alto Uruguai e das Missões, Campus Santo Ângelo, Curso de Enfermagem. Santo Ângelo-RS, Brasil.
\end{abstract}

Submissão: 28-09-2011 Aprovação: 19-02-2013

\section{RESUMO}

Este estudo teve como objetivo investigar fragilidades e agravos vivenciados por trabalhadores com deficiência física no seu ambiente de trabalho. Trata-se de um estudo de caso, de caráter descritivo, de abordagem qualitativa. Os dados foram coletados junto a oito trabalhadores com deficiência física e analisados mediante análise temática. A maioria dos sujeitos pesquisados refere ter encontrado dificuldades na busca do emprego e mencionam o preconceito e a acessibilidade como obstáculos. A maioria não identifica riscos para adoecimento no ambiente de trabalho. As pessoas com deficiência física devem ter conhecimentos acerca de seus direitos e sobre os riscos ocupacionais a que estão expostos, a fim de facilitar meios para a consolidação de uma sociedade cada vez mais inclusiva e promotora de ambiências saudáveis. Os profissionais de saúde devem fazer uma profunda reflexão a fim de que sejam colaboradores para a inclusão saudável de pessoas com deficiência em seus ambientes de trabalho. Descritores: Trabalho; Riscos Ocupacionais; Pessoas com Deficiência.

\begin{abstract}
This study aimed to investigate weaknesses and disorders experienced by workers with physical disabilities in their work environment. It is a descriptive case study, with qualitative approach. Data were collected from eight workers with physical disabilities and analyzed using thematic analysis. Most of the subjects surveyed reported having encountered difficulties in finding employment and mentioned the prejudice and obstacles to accessibility. Most of them do not identify risks for disease in the workplace. People with disabilities should have knowledge about their rights and about the occupational hazards they are exposed, in order to facilitate means for consolidating a society increasingly inclusive and to promote healthy ambience. Health professionals should make a profound reflection on the subject, so that can collaborate for the healthy inclusion of people with disabilities in their jobs.
\end{abstract}

Key words: Work; Occupational Risks; Disabled Persons.

\section{RESUMEN}

Este estudio tuvo como objetivo investigar las debilidades y trastornos sufridos por los trabajadores con discapacidad física en su entorno de trabajo. Se trata de un estudio de caso descriptivo, con enfoque cualitativo. Los datos fueron recolectados a partir de ocho trabajadores con discapacidad física y analizados mediante el análisis temático. La mayoría de las personas encuestadas declararon haber tenido dificultades para encontrar empleo y mencionaran los prejuicios y obstáculos a la accesibilidad. La mayoría no identificaran riesgos de enfermedad en el lugar de trabajo. Las personas con discapacidad física deben tener conocimiento sobre sus derechos y sobre los riesgos laborales a que están expuestos, con el fin de facilitar los medios para la consolidación de una sociedad cada vez más inclusiva y un ambiente de trabajo saludable. Profesionales de la salud deben refletar sobre el tema, a fin de que contribuyan a la inclusión de personas con discapacidad en sus ambientes de trabajo.

Palabras clave: Trabajo; Personas con Discapacidad; Riesgos Laborales. 


\section{INTRODUÇÃO}

O trabalho torna o individuo um ser produtivo, na medida em que contribui para a criação de elementos necessários à sobrevivência humana. Por meio do trabalho, o ser humano cria e modifica a matéria, em beneficio próprio ou de outrem e constrói pilares para o crescimento intelectual e econômico da sociedade. Porém, o trabalho não se restringe apenas como forma de produção, mas como um meio de inserção do sujeito na sociedade, de afirmação das relações interpessoais, exigindo, para tanto, de ambientes e meios apropriados que possibilite a convivência com as adversidades, deficiências e diferenças, características do mundo contemporâneo e globalizado.

É responsabilidade social de toda empresa adotar medidas para o trabalho saudável, tais como análise de risco relativa a qualquer adaptação, ajustamento ou pronta intervenção e encaminhamento de trabalhadores a serviços de tratamento e reabilitação, no caso de deficiência adquirida durante a vida ativa e a inserção da pessoa com deficiência no trabalho deverá ser individual, social e profissional, apoiada por equipe

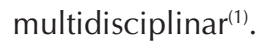

A denominação utilizada para se referir às pessoas com alguma limitação física, mental ou sensorial admite vários formatos ao longo dos anos. Inicialmente eram os "inválidos", "incapazes", "excepcionais" e "pessoas deficientes", até que a Constituição de 1988 incorporou a expressão "pessoa portadora de deficiência". Adota-se, hoje, também, a expressão "pessoas com necessidades especiais" ou "pessoa especial". Porém a expressão "pessoa com necessidades especiais" é um gênero que contém as pessoas com deficiência, mas também acolhe os idosos, as gestantes, enfim, qualquer situação que sugira tratamento diferenciado e a expressão "pessoa portadora de deficiência" foi abandonada, considerando que as deficiências não se portam, estão com a pessoa ou na pessoa, motivo para que se use, atualmente, a forma "pessoa com deficiência"(1).

O processo de exclusão, historicamente atribuído às pessoas com deficiência, deve ser superado a partir da prática de políticas afirmativas e do fortalecimento da noção, pela sociedade, das potencialidades desses indivíduos ${ }^{(1)}$, o que contribui para que grupos minoritários e/ou diferentes da população sejam inseridos e legitimados no seu direito ao trabalho para que, nas diversas formas de organização laboral, demonstrem suas competências e habilidades.

Embora com relativa lentidão, já se pode constatar um significativo número de pessoas com deficiência física inseridas no mercado de trabalho, o que se atribui às reformas nas leis trabalhistas decorrentes das mudanças nos preceitos culturais e críticos da sociedade em relação à inclusão social de grupos minoritários, tais como a homologação da Lei $\mathrm{n}^{\circ} 8.213$, de 24 de julho de $1991^{(2)}$ que, no artigo 93, garantiu cotas de trabalho para pessoas com deficiência nas empresas.

O referido artigo estabelece que a empresa com $100 \mathrm{em}-$ pregados ou mais se obriga a preencher de $2 \%$ a $5 \%$ dos seus cargos com beneficiários reabilitados, ou pessoas com deficiência, habilitadas, sendo que, se a empresa tiver até 200 trabalhadores, deve apor 2\% destes com deficientes; de 201 a 500 trabalhadores o percentual é de 3\%; empresas que empregam 501 a 1000 trabalhadores devem admitir $4 \%$ de trabalhadores com deficiência e, se houver mais de 1000 funcionários, a porcentagem é de $5 \%$ (2).

A fim de contextualizar o tema, é válido referir que é direito das pessoas com deficiência, o desenvolvimento de programas de saúde que ensejem a sua inclusão; assim como, em seleção para inserção no mercado de trabalho, competir com os outros candidatos em concursos públicos desde que o cargo seja compatível com a deficiência que ele apresenta ${ }^{(3)}$. Além disso, entre outras prerrogativas legais, está determinado pela Lei 8.213/91 que o trabalhador com deficiência só poderá ser dispensado após a contratação de substituto em condição semelhante ${ }^{(2)}$.

Porém, a igualdade de direitos, por si só, não é suficiente para tornar as oportunidades acessíveis a todos. "A simples expressão 'Todos são iguais' não passa de mera retórica quando salta aos olhos as diferenças entre seres humanos" (4). Isto posto, legislação específica que assegura ao trabalhador com deficiência condições de relativa igualdade ao sem deficiência é necessária e a sua praticidade depende das condições expostas pela sociedade, exigindo reflexões acerca dos fundamentos decorrentes de conceitos e preconceitos, e demandam mudanças estruturais, financeiras e institucionais afim da melhor adaptação do trabalhador.

Ainda se constatam dificuldades da sociedade para efetivar suas presunções inclusivas; há necessidade de uma constante revisão de suas práticas por vezes excludentes e discriminatórias; e, no mundo do trabalho, é preciso que os gestores avaliem a si e fomentem esta prática no lócus em que atuam para identificarem que ideologias centrais determinam as concepções de deficiência, com vistas a deslocar a percepção individualista de deficiência enquanto anomalia, que enfatiza as limitações, "para uma concepção social inclusiva com a produção de ações de acessibilidade e de afirmação dos locais e ferramentas de trabalho para favorecer a inclusão efetiva das pessoas com deficiência como trabalhadoras com bons potenciais a serem utilizados" (5).

O trabalho decente é admitido pela Organização Internacional do Trabalho como direito de todos, incluindo segurança e saúde, solicitando, dessa forma, ações afirmativas à inclusão de pessoas com deficiência e sua adequada manutenção no mercado de trabalho( ${ }^{(1)}$. As ações afirmativas compreendem instrumentos capazes de concretizar as várias determinações implicadas nos direitos das pessoas com deficiência e envolvem políticas públicas e privadas de combate a discriminação e, de igualdade de acesso a bens fundamentais ${ }^{(4)}$, o que, ironicamente, pode despertar tensão entre os trabalhadores, visto que uma ação que proporcione às pessoas com deficiência melhores condições de inclusão no trabalho pode ser vislumbrada como privilégio ${ }^{(6)}$.

Como instrumentos facilitadores à inclusão adequada de trabalhadores com deficiência podem-se citar algumas normas reguladoras, incluindo-se o Programa de Controle Médico de Saúde Ocupacional (PCMSO) e o Programa de Prevenção de Riscos Ambientais (PPRA), dentre outros, que, articulados, conferem preservação da saúde e integridade 
dos trabalhadores em geral e em especial das pessoas com deficiência ${ }^{(1)}$.

A acessibilidade a pessoas com deficiência há pouco tempo vem sendo ressaltada e mesmo assim, ainda são inúmeras as dificuldades de remodelação do panorama atual para incluir todos como membros de uma mesma sociedade e, portanto com os mesmos direitos de cidadania. A lei para inclusão de pessoas com deficiência física no mercado de trabalho existe desde a década de 90 , contudo ainda tem-se muito a avançar quanto à efetiva inclusão da pessoa com deficiência no mercado de trabalho.

Observa-se que há dificuldades internas e externas ao ambiente de trabalho do sujeito com deficiência física. No ambiente externo, dificuldades na acessibilidade física, como a falta de rampas em determinadas ruas, prédios, organizações públicas e privadas; número pequeno ou inexistente de transportes coletivos adaptados em determinadas regiões; relações nem sempre cordiais, transparecendo preconceitos e desobrigação à solidariedade, impaciências, entre outras, ainda são frequentemente observadas. Pretende-se, com este estudo, investigar dificuldades no cenário interno do trabalho. Sendo assim pergunta-se: que dificuldades são encontradas no ambiente de trabalho da pessoa com deficiência física, capazes de fragilizá-lo ou de causar agravos à sua saúde?

É oportuno considerar que deficiência física, objeto deste estudo, é "a alteração completa ou parcial de um ou mais segmentos do corpo humano, acarretando o comprometimento da função física" (1).

Acredita-se que a inserção saudável de pessoas com deficiência física no mercado de trabalho deriva de ações sociais e institucionais. Neste sentido, este estudo tem como objetivo investigar fragilidades e agravos vivenciados por trabalhadores com deficiência física no seu ambiente de trabalho, o que se reveste de relevância na medida em que propõe uma reflexão acerca da inclusão no trabalho, de forma humanizada e saudável, a partir da singularidade e subjetividades de sujeitos.

\section{PERCURSO METODOLÓGICO}

Trata-se de um estudo de caso descritivo, com abordagem qualitativa. A pesquisa foi realizada junto a sujeitos com deficiência física, que trabalham em municípios situados na região noroeste do estado do Rio Grande do Sul, convidados aleatoriamente.

Os critérios para a escolha dos participantes foram: ser pessoa com deficiência física, estar inserido no mercado de trabaIho e aceitar participar. Aos oito participantes da pesquisa foi apresentado um Termo de Consentimento Informado Livre e Esclarecido, em duas vias, onde constavam os objetivos da pesquisa incluindo informações sobre sua livre participação e garantia de sigilo e anonimato. A fim de garantir o sigilo e anonimato, os sujeitos foram identificados como letras do alfabeto Grego.

A coleta de dados foi realizada após a aprovação pelo Comitê de Ética em Pesquisa da Universidade Regional Integrada do Alto Uruguai e das Missões, Campus de Santo Ângelo, Protocolo $\mathrm{n}^{\circ} 0065-4 / \mathrm{PPH} / 10$, respeitando-se os preceitos éticos da pesquisa envolvendo seres humanos.
Os dados foram coletados no primeiro semestre de 2011, mediante entrevista semiestruturada com a finalidade de beneficiar a livre expressão dos sujeitos e instigar a abordagem da temática em estudo. As perguntas foram elaboradas pelos pesquisadores e versaram sobre as dificuldades e agentes encontrados no ambiente de trabalho da pessoa com deficiência, capazes de fragilizá-lo ou de causar agravos à sua saúde.

O registro das informações se efetivou mediante a utilização de gravador. Posteriormente, as falas foram transcritas e submetidas a técnica de análise de conteúdo, na modalidade de análise temática ${ }^{(7)}$. A transcrição e organização dos relatos obtidos pelas entrevistas compuseram a ordenação dos dados e a classificação deu-se a partir da leitura exaustiva destes materiais, identificando-se estruturas de relevância, de onde emergiram três categorias: Dificuldades na inclusão e no cotidiano do mercado de trabalho; Legislação e deficiência; e Exposição a riscos no ambiente de trabalho.

\section{RESULTADOS E DISCUSSÃO}

Foram pesquisados oito trabalhadores com deficiência física, dos quais sete exercem atividade laboral assalariada e um, voluntariado. Destes, cinco trabalham no serviço púbico e três no serviço privado. A média de idade é de 48 anos e a média do tempo de trabalho é de 17,5 anos. Os sujeitos são, em sua maioria, do sexo masculino. As ocupações dos sujeitos envolvem coordenação de Estratégia de Saúde da Família, administrador de jornal, conselheiro tutelar, agente administrativo, trabalhador em lar de idosos e atividades junto à justiça do trabalho.

\section{A. Dificuldades na inclusão e no cotidiano do mercado de trabalho}

A maioria dos sujeitos mencionou dificuldades na inclusão no mercado de trabalho, atribuídas, por grande parte destes, ao preconceito.

[...]é muito difícil com certeza. Preconceito, isso aí existe até hoje. Depois foi dificuldade de acesso, mas o maior eu ultrapassei. Também é difícil você chegar de cadeira de roda num local e pedir emprego e alguém dar emprego pra você (Alfa).

[...]são muitas[dificuldades], até existia uma certa rejeição da sociedade que tinha essa mentalidade[...] Mas aí, com o tempo, foi passando eu fui achando que e possível,' né ' (Gama).

[...]o velhinho ficou com pena de mim e mandou me contratar e me contrataram, só que me deixavam no escritório e lá eu dormia o dia inteiro; não me davam serviço porque achavam que eu não podia trabalhar (Eta).

[...] uma dificuldade vamos dizer assim é a desconfiança da tua capacidade, eles acham por que tuas pernas não funcionam o cérebro também seria afetado. Então tu sempre passa por um período em que as pessoas ficam desconfiadas depois admiradas [...] "apesar de tudo ela pode, ela faz, ela 
consegue", daí depois vem certo reconhecimento e até o respeito das pessoas, mas é um processo tudo isso ai (Zeta).

Embora a maioria tenha sofrido com o preconceito e a exclusão, os respondentes sentem-se, atualmente, incluídos no mercado de trabalho, o que denota um processo de superação de dificuldades e inserção em espaços comuns a todos os cidadãos. Acredita-se que o sujeito contribui para o processo inclusivo, no momento em que apreende a legislação que lhe assegura direitos, que compreende as tramas da alteridade e desenvolve suas habilidades e competências para minimizar as diferenças.

Outro aspecto enfatizado por grande parte dos sujeitos foi que, num primeiro momento, só conseguiram entrar para o mercado de trabalho por influência política ou por intermediação de amigos e familiares, o que, de alguma forma, configura uma espécie de exclusão, pois precisaram de terceiros para ter acesso ao direito fundamental do cidadão ao trabalho.

Na sociedade capitalista, em que o trabalho gira em torno do lucro, o trabalhador é visto como mera mercadoria, ou seja, deve ser forte e saudável. Ao contrário, podem se tornar um obstáculo para a produção. Nesta perspectiva, o corpo com lesões ou deficiências não estaria apto ao regime de exploração da força de trabalho sobre a qual a destreza física está posta como um fator fundamental à inserção plena na arquitetura de um sistema dominante de produção, criador do modus operandi moderno ${ }^{(8)}$. Sendo o trabalhador com deficiência uma pessoa provida de algumas "disfuncionalidades", "falhas", limitações, na lógica capitalista, ele pode ser visto como um entrave à produção, o oposto à eficiência e à produtividade, considerando que, neste modelo, é atribuído valor à agilidade e ao tempo, numa distorcida lógica de que "triunfarão apenas os mais aptos e capazes, justamente aqueles que podem se adaptar às novas exigências laboriosas" (8). Entretanto, é oportuno salientar, nesta discussão, o autopreconceito na busca do emprego.

[...] eu próprio pensava isso que o portador de deficiência era pra ficar em casa, era aquela mentalidade antiga como se fosse uma pessoa inútil(Gama).

\section{[...] quando entrei [no trabalho] a gente tinha, parece... um} preconceito [...] (Teta.).

Observa-se que a falta de conhecimento dos seus direitos de cidadão, de qualificação, o preconceito e o autopreconceito, além do ônus assumido pelo empregador na adaptação do ambiente ao trabalhador com deficiência, podem ser fatores impeditivos da inserção desses sujeitos no mercado de trabalho. Submetidos a tais condições, que impõem facilidades para uns e dificuldades para outros, cabe a esse sujeito elaborar estratégias de resistência para fortalecer sua personalidade, na busca pela inclusão social ${ }^{(9)}$.

O preconceito foi evidenciado como uma dificuldade, apesar do processo de exclusão, atribuído historicamente às pessoas com deficiência, não se manter tão rigoroso atualmente, porém a visibilidade se torna exacerbada na deficiência física por estar explícita na aparência e funcionalidade. Ainda existe associação entre deficiência e significados negativos, depreciativos ou em sentimentos de piedade interpretado como imperfeição, incapacidade, desvantagem e relacionado a um conceito de desvalorização social ${ }^{(10)}$.

E a visibilidade ou invisibilidade da diferença podem determinar a dinâmica das inter-relações sociais na vida da pessoa com deficiência física; ocultar tal diferença protege da exposição, mas ao mesmo tempo induz ao temor pela iminência de ser descoberta ${ }^{(10)}$. Há necessidade de revisão por parte da sociedade de conceitos e pré-conceitos ainda existentes, e a disposição de oferecer credibilidade e confiança a esses sujeitos.

Apesar do seu potencial, esses sujeitos se percebem diferentes, pois são socializados por meio de um discurso cujos sentidos encerram as crenças e valores da pessoa sem deficiência, o que está retratado no meio social. É a tolerância com a pessoa com deficiência física por temer a ação punitiva da $\mathrm{lei}^{(9)}$. Cabe à pessoa empossar-se de seus direitos e a sociedade respeitá-los, (re) criando oportunidades em que o sujeito possa demonstrar suas competências de modo a reduzir o preconceito a desconfiança acerca da sua capacidade.

Um estudo verificou que nas práticas de inclusão no trabaIho, ocorrem situações, denominadas pelo autor, de "ironias da desigualdade" e envolvem a ameaça de chefes a empregados, obrigando-os a tratar os deficientes como normais; a visão da deficiência como uma virtude que facilita o acesso ao emprego; e o uso do deficiente, pela sua superação de limites, como exemplo de bom trabalhador e fator de disciplinamento e internalização das regras produtivas, o que apontam para a necessidade de um atencioso aprimoramento das políticas públicas e privadas, de modo a viabilizar a essencial inclusão no trabalho ${ }^{(6)}$.

Além do preconceito, alguns relataram dificuldades no ambiente de trabalho quanto à acessibilidade, em especial a locomoção.

[...] Como meu trabalho exige deslocamento de carro, então não é como uma pessoa normal, pegar e embarcar dentro de um carro e sair, requer mais tempo [...] depende de o motorista ou colega ajudar e aí tem mais a questão da boa vontade, por que a gente não vai pedir ajuda para quem tu sente que não está te ajudando de boa vontade [...] (Gama).

Locomoção é uma dificuldade, quando chove, acesso as empresa, acesso aos banheiros que não existem na cidade, acesso as rampas nas calçadas que são todas mal feitas (Épsilon).

A acessibilidade inadequada retrata barreiras que impedem o principal e mais básico dos exercícios dos direitos de qualquer cidadão, a viabilidade de deslocar-se livremente $^{(11)}$. $\mathrm{O}$ direito à acessibilidade, não torna, essencialmente, uma sociedade acessível a todos, mas diminui as iniquidades existentes para as pessoas com deficiência, permitindo-lhes oportunidades, abrindo espaços de autonomia e conquistas; expressa a necessidade de uma sociedade constituída pelo direito de todos de ir e vir, de usufruir de bens e serviços, de trabalhar etc. Cabe salientar que devem advir das organizações públicas e privadas iniciativas que facilitem o acesso a esses sujeitos, contribuindo para um trabalho saudável e com 
segurança, validando as normativas legais expostas na legislação que ampara o deficiente físico ${ }^{(6)}$.

[...] p primeira dificuldade que tive foi a própria infraestrutura[...], essa era a primeira dificuldade que tinha no geral e nas lojas não tinham lugar nem sequer para uma rampinha quem dirá em contratar um funcionário, se nem como cliente eles lembravam do deficiente, então tinha bastante dificuldade mesmo. Então a pessoa deficiente, nesta área, ou partia pra fazer um artesanato e sempre achava alguma alternativa 'né', mas aquele emprego no comércio, o emprego convencional realmente as pessoas, assim, nem cogitavam o deficiente. Eles queriam uma pessoa que de repente pudesse fazer outras atividades que achavam que o deficiente não pudesse fazer, por que aquela pessoa de repente, volta e meia estaria doente, não poderia vir, então realmente a dificuldade foi grande. (Zeta).

Observou-se que a maioria dos entrevistados possui carros ou dispositivos de locomoção, tais como: cadeiras elétricas e carros adaptados. São pessoas que não usam/dependem de transporte público e com condição econômica favorável. Um estudo que analisou políticas e práticas de inclusão da pessoa com deficiência física no mercado de trabalho em Salvador (BA), demonstrou que nenhuma outra questão foi tão mencionada quanto a acessibilidade, enquanto elemento fundamental e fortalecedor da desigualdade de oportunidades ${ }^{(6)}$.

\section{B. Legislação e deficiência}

Sabe-se que há legislação específica que ampara a pessoas com deficiência física no mercado de trabalho, a qual lhe garante cotas nas empresas e oportunidades para competir com outros candidatos em concursos públicos, por exemplo. Acredita-se que a reforma e/ou homologação de leis que asseguram o direito ao trabalho e a condições respectivas a pessoa com deficiência, possibilitou a inclusão desta população no mercado de trabalho, e oportunizou espaços para que este sujeito pudesse demonstrar suas habilidades e competências em ambientes favoráveis à sua adaptação, porém nem todos a conhecem na sua totalidade. Dentre os depoentes, a maioria refere ter somente algum conhecimento sobre a lei.

Alguma coisa eu já me informei, eu sei que existe, mas a única coisa que eu sei é a porcentagem, que as empresas que tiver mais que 100 funcionários [precisam empregar deficiente], agora assim, a lei, eu não conheço (Beta).

Alguma coisa sim, não por total, mas algum conhecimento eu tenho [...] muitas vezes a gente não tem conhecimento nenhum [...] a questão do trabalho eu também não imaginava que o portador de deficiência tinha esses direitos (Gama).

Não tenho assim um conhecimento profundo, mas sei que há partes que ampara o portador de deficiência (Épsilon).

Alguma coisa sim, mas não muito por que a gente teria que parar e ter um tempo para ler, a gente sabe que tem bastante coisa que está no papel e na realidade não vê cumprir tudo que as pessoas passam para a gente [...] (Teta).

Observa-se, nessas falas, o descaso/desinteresse por parte dos próprios sujeitos, no que tange à busca por informações adequadas e fidedignas acerca da legislação que os ampara, conhecimento este que se torna relevante no momento em que proporciona segurança para solicitar o cumprimento da mesma.

As pessoas com deficiências conquistaram leis que garantem direitos de cidadania, "mas ainda existem desafios relativas à saúde, educação, profissionalização e a inserção no mercado de trabalho( ${ }^{(9)}$. Está disposto na Política Nacional de Integração à Pessoa Portadora de Deficiência, incluir a pessoa com deficiência, respeitada as suas peculiaridades, em todas as iniciativas governamentais relacionadas à educação, à saúde, ao trabalho, à edificação pública, à previdência social, à assistência social, ao transporte, à habitação, à cultura, ao esporte e ao lazer ${ }^{(3)}$.

Para os sujeitos estudados, a sociedade não respeita a legislação que os ampara. Pode-se inferir que é um processo em construção a inclusão e a integração desses sujeitos.

A inclusão das pessoas com deficiência no mercado de trabalho, segundo a legislação ${ }^{(3)}$, deve ocorrer em condição de igualdade com os demais trabalhadores, disponibilizando-se procedimentos e apoios especiais conforme o grau de incapacidade, além de oferecer ambientes favoráveis a adaptação do sujeito dispensando tratamento humanitário e respeito aos direitos dessas pessoas de trabalharem com dignidade e cidadania, o que é cumprido em parte, conforme os depoimentos:

Em parte, não total, né, pois a gente vê a própria questão de concursos para trabalho [...] aconteceu comigo há algum tempo atrás quando me inscrevi em um concurso e eu tinha que ter as mesmas condições que as pessoas normais, senão eu seria reprovado e se sabe que o portador de deficiência não tem as mesmas condições que uma pessoa norma (Gama).

[...] se eles cumprem acho que não, então a questão dos órgãos públicos, agora tipo assim, algum lá que falta um dedinho ou é um pouquinho manco, esses tudo bem, mas uma pessoa assim com uma deficiência maior, eles não costumam contratar (Zeta).

É oportuno evidenciar que, a legislação dispõe sobre as possibilidades de inserção da pessoa com deficiência no mercado de trabalho e, os "meios usados para a contratação de pessoa que, devido ao seu grau de deficiência, transitória ou permanente, exija condições especiais, tais como jornada variável, horário flexível, proporcionalidade de salário, ambiente de trabalho adequado às suas especificidades" são procedimentos especiais usados para esta inserção(3) e que, nem sempre são cumpridas. $O$ trecho da fala a seguir retrata a opinião acerca do cumprimento ou não da legislação.

Uma parte bem pequena [cumpre a lei], na verdade. Nós continuamos encontrando dificuldade [...](Alfa). 
Embora não se observe no cotidiano, há normas gerais e critérios básicos para a promoção da acessibilidade das pessoas com deficiência ou com mobilidade reduzida. Refere a lei que deve ser dispensado atendimento prioritário a estas pessoas, tais como assentos preferenciais sinalizados, espaços e instalações acessíveis, mobiliário adaptado, local e pessoal capacitado para atendimento, área especial para embarque e desembarque destas pessoas, sinalização ambiental para orientação, divulgação visível do direito de atendimento prioritário destas pessoas, admissão de entrada e permanência de cão-guia, entre outros aspectos ${ }^{(12)}$.

A legislação que ampara o sujeito com deficiência física é bem clara quando lhe assegura uma inserção adequada com instrumentos facilitadores procedendo de mudanças institucionais, sociais e financeiras que demandem uma adaptação saudável desse sujeito. Apesar da legislação vigente, ainda se encontram dificuldades relacionadas ás mudanças que deveriam ser instituídas nas empresas públicas ou privadas e sociedade em geral, tais como rampas, banheiros adaptados, portas mais largas e a valorização do sujeito com deficiência.

Isto posto, profissionais de saúde precisam conhecer o cotidiano desses sujeitos e dos seus familiares para contribuir na busca de estratégias de enfrentamento dos problemas que influenciam na sua inclusão social, além de apropriarem-se de conhecimentos acerca da legislação que os ampara, para atuar no processo de reabilitação ajudando-os, seja na preservação da sua capacidade funcional, na compensação da perda de uma função ou limitação a fim de facilitar reajustes sociais ${ }^{(9)}$.

\section{Exposição a riscos no ambiente de trabalho}

Dos sujeitos pesquisados a maioria refere não estar exposto a nenhum tipo de risco para adoecer ou sofrer acidente. Aqueles que referem estar expostos a risco biológicos, caracterizados pela exposição a microrganismos, relaciona-se às atividades junto a usuários na atenção à saúde. Alguns sujeitos referiram o risco psicossocial, caracterizada pelo estresse, decorrente de pressão no trabalho, aludindo que:

Todo mundo que trabalha na área de saúde está propicio a correr riscos da saúde da gente [...](Alfa).

[... a questão da pressão que eu falei antes de trabalho ela é um risco para adoecer, ela é um risco para a doença e é um risco forte, eu tenho consciência disso e assim como eu os demais, todos, do mais alto ao menor, lá dentro todos tem conhecimento disto... é isso que nós temos, o nosso risco é pressão é controlar o estresse (Eta).

Riscos psicossociais referem-se a riscos que podem alterar a saúde psíquica do trabalhador, tais como ritmo exaustivo de trabalho, falta de reconhecimento e valorização, estresse. Algumas categorias de trabalho se mantém diariamente sobre forte pressão psíquica causando uma carga elevada de sofrimento psíquico no trabalhador. Os riscos biológicos, caracterizados pela exposição a microrganismos, para trabalhadores que atuam na área da saúde é uma exposição permanente, visto que diariamente mantém contato com pessoas com doenças transmissíveis ${ }^{(13)}$

No que concerne ao conhecimento sobre a existência de programa de proteção de riscos ambientais (PPRA) na empresa, $100 \%$ dos sujeitos desconhecem a existência, sendo que, destes, apenas uma minoria refere existir pessoas específicas para o desenvolvimento de atividades de prevenção direcionada aos trabalhadores.

Oportuno é salientar que é obrigação do empregador proporcionar um ambiente laboral saudável a todo o trabalhador, o que não influi na contratação de um trabalhador com deficiência. As adaptações necessárias deverão ser feitas pela empresa, que deve zelar pela segurança e saúde de todos os seus colaboradores, com deficiência ou não, eliminando barreiras e limitações de ordem física ou social ${ }^{(4)}$.

Além de a totalidade dos sujeitos mencionarem que nunca adoeceu em decorrência do trabalho, uma parte referiu que nunca tirou férias ou afastou-se do trabalho em decorrência de adoecimento.

[...] eu nunca fiquei doente, assim, por causa do meu trabalho e até eu nunca tive atestado médico por causa de trabalho, até hoje (Alfa).

[...] eu nunca adoeci no trabalho ainda, até hoje, dos 22, 23 anos [de trabalho], nunca adoeci, nunca tive problemas $[. .$.$] (Eta).$

Percebeu-se, durante a entrevista, a grande satisfação que o trabalho causa na vida destes trabalhadores, o que pode ser justificado pela superação de seus limites pessoais e pela dificuldade na busca pelo emprego. Pode-se inferir que os riscos são desconsiderados ou negligenciados por estes trabalhadores.

Tais resultados provocam muitas indagações e objetos para novos estudos. Isto posto, é oportuno alguns questionamentos que podem ser parafraseados de outros autores ${ }^{(14)}$ : Qual a parcela de responsabilidade dos profissionais de saúde diante dos processos de exclusão e desigualdade social e que contribuições estão sendo dadas por esta ciência para o fortalecimento da cidadania e a promoção da saúde dos sujeitos expostos a estas vulnerabilidades? Algumas estratégias são sugeridas, tais como: "pesquisa e intervenção nas realidades socialmente vulneráveis; propostas criativas e interdisciplinares de intervenção social; aproximação do saber acadêmico ao popular e, entre outros, 'laboratórios sociais' para a compreensão do mundo real do 'viver a vida', em busca do 'viver mais saudável'".

\section{CONSIDERAÇÕES FINAIS}

Com os achados desta pesquisa foi possível compreender que o preconceito ainda hoje é uma das grandes dificuldades que a pessoa com deficiência física encontra na busca pelo emprego, assim como a acessibilidade, decorrente de pressupostos históricos segundo os quais o deficiente físico era tarjado como um ser incapacitante devido à sua limitação física corporificada na aparência. O preconceito aflige diretamente 
a autoestima desses sujeitos, que são afrontados por suas limitações físicas, configurando-o como um sujeito diferente das pessoas que se julgam normais e tornando-os inseguros, além de que, atitudes desta natureza contribuem para fomentar a exclusão social.

Mesmo sob preconceito e autopreconceito, os sujeitos sobrepujaram tais dificuldades na busca pelo emprego e encontram-se satisfeitos com suas atividades laborais, referindo-se ao trabalho como uma grande conquista, motivo de superação e algo que traz alegria em suas vidas.

Preocupante foi o dado demonstrado sobre o desconhecimento dos riscos ocupacionais, considerando que, mesmo ínfimo, todos os trabalhadores estão expostos a algum risco ocupacional. O demérito referido pelos trabalhadores no que se referem aos riscos nos remete a uma apreensão, porque ao ser negligenciado, o adoecimento pode advir sem relação com o trabalho a, assim, não se ter elementos para intervenção.

Por outro lado, satisfaz conhecer o quanto o trabalho é prazeroso para esses sujeitos e, talvez, possa ser um motivo do julgamento negativo sobre o risco ocupacional, o que pode ser confirmado nas falas referentes a não tirar férias e/ou licença para tratamento de saúde, além de que, percebeu-se manifestação de gestos e expressão de satisfação ao falar sobre isso.

Os dados obtidos anulam preceitos formados por empregadores que julgam a pessoa com deficiência física como alvos fáceis de absenteísmo ou que relacionam a deficiência com diminuição de eficiência. Todos os sujeitos entrevistados desempenham atividades tais como outros colaboradores e estão capacitados para desenvolvê-lo, no entanto possuem conhecimentos deficientes acerca da legislação que os ampara e facilita a adaptação de suas limitações.

É oportuno salientar que os sujeitos pesquisados possuíam mecanismos facilitadores, no cotidiano do trabalho, e condições financeiras favoráveis. Sugere-se estudos enfatizando a população com deficiência e desfavorecida, levando em conta a escassez de produção científica, o que torna possível verificar possíveis obstáculos na inclusão ao mercado de trabalho e outras dificuldades.

Cabe salientar que devem ser oportunizados ao trabalhador com deficiência física conhecimentos acerca de seus direitos e sobre os riscos ocupacionais a que estão expostos, a fim de facilitar meios para a consolidação de uma sociedade cada vez mais inclusiva e promotora de ambiências saudáveis. A principal limitação encontrada no decorrer da pesquisa foi a dificuldade na busca de sujeitos que se adequassem aos critérios de inclusão propostos e a aceitação, por parte de alguns gestores, da realização da pesquisa junto aos seus colaboradores.

Pesquisas desta natureza devem ser mais exploradas no campo da enfermagem, considerando a importância do saber acerca da diversidade e temas afins para o cuidado humanizado e atento à equidade que a sociedade inclusiva exige.

\section{REFERÊNCIAS}

1. Ministério do Trabalho e Emprego [homepage na internet. A inclusão de pessoas com deficiência no mercado de trabalho [acesso em 20 abr 2011]. Disponível em: http:// www.mte.gov.br/fisca_trab/inclusao/default.asp

2. Presidência da República (Brasil). Casa Civil. Subchefia para Assuntos Jurídicos. Lei no 8.213, de 24 de julho de 1991. Dispõe sobre os Planos de Benefícios da Previdência Social e dá outras providências. Diário Oficial da União [acesso em 20 jun 2010]. Disponível em: http:// www.planalto.gov.br/ccivil 03/Leis/L8213cons.htm

3. Presidência da Republica (Brasil ). Casa civil. Subchefia para Assuntos Jurídicos. Decreto no 3.298, de 20 de dezembro de 1999. Dispõe sobre a Política Nacional para a Integração da Pessoa Portadora de Deficiência. Diário Oficial da União [acesso em 18 jun 2010]. Disponível em: http://www.planalto.gov.br/ccivil/decreto/ d3298.htm.

4. Araujo EABS, Basso F. O conceito de pessoa com deficiência e seu impacto nas ações afirmativas brasileiras no mercado de trabalho. In: Anais do XIX Encontro Nacional do CONPEDI; 2010 jun; Fortaleza,(CE). Fortaleza 2010. P. 8841-8859.

5. Oliveira AB. A determinância dos fatores sócio-históricos em suas subjetivações na gestão de profissionais com deficiência nas organizações. Rev Economia Gestão 2012;12(30):79-96.
6. Vasconcelos FD. O trabalhador com deficiência e as práticas de inclusão no mercado de trabalho de Salvador, Bahia. Rev Bras Saúde Ocup 2010;35(121):41-52.

7. Minayo MCS. O desafio do conhecimento: pesquisa qualitativa em saúde. 6. ed. São Paulo: Hucitec; 2008.

8. Picolo GM, Mendes EG. Nas pegadas da história: tracejando relações entre deficiência e sociedade Rev Educ Espec 2012;25(42):29-42.

9. França ISX, Pagliuca LMF. Inclusão social da pessoa com deficiência: conquistas, desafios e implicações para a enfermagem. Rev Esc Enferm USP 2009;43(1):178-85.

10. Martins JA, Barsaglini RA. Aspectos da identidade na experiência da deficiência física: um olhar socioantropológico. Interface Comun SaúdeEduc 2011;15(36): 109-22.

11. Siqueira FCV, Facchini LA, Silveira DS, Piccini RX, Thumé E, Tomasi E. Barreiras arquitetônicas a idosos e portadores de deficiência física: um estudo epidemiológico da estrutura física das unidades básicas de saúde em sete estados do Brasil. Ciênc Saúde Coletiva 2009;14(1):39-44.

12. Presidência da República ( Brasil). Casa civil. Subchefia para Assuntos Jurídicos. Lei $n^{\circ} 5.296$, de 2 de dezembro de 2004. Regulamenta as Leis $\mathrm{n}^{\text {os }} 10.048$, de 8 de novembro de 2000, que dá prioridade de atendimento às pessoas que especifica, e 10.098, de 19 de dezembro de 2000, que estabelece normas gerais e critérios básicos para a promoção da acessibilidade das pessoas 
portadoras de deficiência ou com mobilidade reduzida. Diário Oficial da União [acessado em 10 jun 2010]. Disponível em: http://www.planalto.gov.br/ccivil_03/ ato2004-2006/2004/decreto/d5296.htm

13. Gallas SR, Fontana RT. Biossegurança e a enfermagem nos cuidados clínicos: contribuições para a saúde do trabalhador. Rev Bras Enferm 2010;63(5):786-92.

14. Erdmann AL, Backes MTS, Backes DS, Koerich MS; Baggio MA, Carvalho JN, et al. Gerenciando uma experiência investigativa na promoção do "viver saudável" em um projeto de inclusão social. Texto Contexto Enferm 2009;18(2):369-77. 